\title{
Exclusion criteria and adverse events in perioperative trials of tranexamic acid in cardiac surgery: a systematic review and meta-analysis
}

\section{Critères d'exclusion et événements indésirables dans les études périopératoires sur l'utilisation d'acide tranexamique en chirurgie cardiaque : revue systématique et méta-analyse}

\author{
Simonne Khair, BSc 다 - Iris Perelman, BHSc $\cdot$ Jeffrey Yates, MD $\cdot$ Joshua Taylor, BSc $・$ \\ Jacinthe Lampron, MD, FRCSC • Alan Tinmouth, MD, FRCPC • Elianna Saidenberg, MD, FRCPC
}

Received: 13 November 2018/Revised: 2 March 2019/Accepted: 23 March 2019/Published online: 17 May 2019

(C) Canadian Anesthesiologists' Society 2019

\begin{abstract}
Purpose Tranexamic acid (TXA) reduces perioperative blood loss and transfusion requirement following cardiac surgery. Nevertheless, TXA remains underutilized because of concerns regarding development of adverse events. We conducted a systematic review to determine which patients are commonly excluded from TXA cardiac surgery clinical trials to determine if there are patient groups lacking safety data on TXA.

Methods The databases Medline, EMBASE, and the Cochrane Central Register of Controlled Trials were
\end{abstract}

Electronic supplementary material The online version of this article (https://doi.org/10.1007/s12630-019-01393-w) contains supplementary material, which is available to authorized users.

S. Khair, BSc $\cdot$ J. Yates, MD $\cdot$ J. Taylor, BSc

Faculty of Medicine, University of Ottawa, Ottawa, Canada

I. Perelman, BHSc

Faculty of Medicine, University of Ottawa, Ottawa, Canada

Clinical Epidemiology, Ottawa Hospital Research Institute, Ottawa, Canada

J. Lampron, MD, FRCSC - A. Tinmouth, MD, FRCPC .

E. Saidenberg, MD, FRCPC $(\square)$

Faculty of Medicine, University of Ottawa, Ottawa, Canada

e-mail: esaidenberg@toh.ca

Clinical Epidemiology, Ottawa Hospital Research Institute, Ottawa, Canada

Ottawa Hospital, 501 Smyth Rd, Ottawa, ON K1H 8L6, Canada searched until September 2017. Eligible studies were randomized-controlled trials (RCTs) administering systemic TXA perioperatively to patients undergoing any cardiac surgery. Our primary outcome was the exclusion criteria for each $R C T$, and the secondary endpoint was TXA safety. A descriptive synthesis was performed to analyze the exclusion criteria. TXA safety was assessed with meta-analysis.

Principal findings Seventy eligible RCTs were included. The most common reasons for excluding patients from TXA cardiac surgery trials were major hepatic, renal, or cardiac comorbidities ( $76 \%$ of studies). Meta-analysis showed that TXA did not increase the risk of adverse events compared with placebo or no intervention (risk ratio, 0.97; 95\% confidence interval, 0.88 to 1.07), including thrombosis and seizure.

Conclusion We found that systemic TXA is safe to use in cardiac surgery. Certain patient groups are frequently excluded from TXA cardiac surgery trials, and may consequently have limited efficacy and safety data on TXA. Further research in these patient groups may be needed; nevertheless, for many patient populations there are sufficient data to inform evidence-based guidelines for TXA use in cardiac surgery.

Trial registration PROSPERO (CRD42017060971); registered 4 April, 2017.

\section{Résumé}

Objectif L'acide tranexamique (ATX) réduit les pertes sanguines périopératoires et les besoins transfusionnels après une chirurgie cardiaque. L'ATX demeure toutefois sous-utilisé en raison de craintes quant à la survenue 
d'événements indésirables. Nous avons réalisé une revue systématique afin d'identifier les patients le plus fréquemment exclus des études cliniques sur l'utilisation d'ATX en chirurgie cardiaque pour déterminer si les données d'innocuité de l'ATX sont insuffisantes pour certains groupes de patients.

Méthode Des recherches ont été effectuées dans les bases de données Medline, EMBASE et dans le Cochrane Central Register of Controlled Trials pour en tirer les études publiées jusqu'en septembre 2017. Pour être éligibles, les études devaient être des études randomisées contrôlées (ERC) examinant l'administration systémique d'ATX en période périopératoire à des patients subissant une chirurgie cardiaque, quelle qu'elle soit. Le critère d'évaluation principal de notre étude s'intéressait aux critères d'exclusion de chaque ERC, et le critère d'évaluation secondaire à l'innocuité de l'ATX. Une synthèse descriptive a été réalisée afin d'analyser les critères d'exclusion. L'innocuité de l'ATX a été évaluée par une méta-analyse.

Constatations principales Soixante-dix ERC éligibles ont été incluses dans notre revue. Les raisons les plus fréquentes d'exclusion de patients des études d'ATX en chirurgie cardiaque étaient des comorbidités hépatiques, rénales ou cardiaques majeures (76\% des études). La méta-analyse a démontré que l'ATX n'augmentait pas le risque d'événements indésirables par rapport au placebo ou à toute autre intervention (risque relatif, 0,97; intervalle de confiance $95 \%, 0,88$ à 1,07), y compris le risque de thrombose ou de convulsion.

Conclusion Nous avons observé que l'ATX par voie systémique peut être utilisé en toute sécurité en chirurgie cardiaque. Certains groupes de patients sont fréquemment exclus des études portant sur l'ATX en chirurgie cardiaque, et les données sur l'efficacité et l'innocuité de l'ATX dans ces populations pourraient par conséquent être limitées. Des recherches supplémentaires dans ces groupes pourraient être nécessaires; toutefois, les données pour plusieurs populations de patients sont suffisantes pour établir des directives fondées sur les données probantes concernant l'utilisation d'ATX en chirurgie cardiaque.

Enregistrement de l'étude PROSPERO
(CRD42017060971); enregistrée le 4 avril 2017.

(CRD42017060971); enregistrée le 4 avril 2017.

Cardiac surgery can result in substantial blood loss, putting patients at increased risk for requiring blood transfusions and even reoperation because of bleeding, both of which can result in worsened postoperative outcomes. ${ }^{1,2}$ One of a number of strategies used to minimize perioperative bleeding is administration of tranexamic acid (TXA), an anti-fibrinolytic agent that binds to lysine residues on plasminogen to prevent its conversion to plasmin, thereby inhibiting fibrinolysis. ${ }^{3,4}$ Clinically, TXA has showed clear benefit in reducing blood loss in cardiac surgeries, performed with or without the use of cardiopulmonary bypass. $^{3-6}$ TXA also significantly reduces the need for perioperative blood transfusion, thus reducing patient exposure to the infectious and non-infectious risk of transfusion. ${ }^{3,4,7,8}$ In addition to being efficacious, TXA is inexpensive, costing about 10.00 CAD per $1 \mathrm{~g}$ in Canada, $£ 5.70$ per $1 \mathrm{~g}$ in the UK, and 7.20 USD per $1 \mathrm{~g}$ in the Unites States. $^{9}$

Despite the efficacy of TXA at reducing perioperative blood loss and transfusion requirement, there remain uncertainties and concerns regarding complications, including thrombotic events and seizures. ${ }^{1,10-14}$ These are important barriers to the more widespread use of TXA and currently there are no evidence-based recommendations outlining from which patients TXA should be withheld because there is insufficient evidence to estimate risks of the therapy. Current blood conservation guidelines for cardiac surgery make Class 1 Level A recommendations for the use of TXA. ${ }^{12,13}$ Nevertheless, the guidelines state that the risk of adverse events such as seizures remains uncertain. $^{12,13}$ We hypothesize that physicians concerned about complications may withhold TXA from patients who are likely to benefit from its use. To help physicians make informed decisions about TXA use, it is important to know if there are specific patient groups for whom risk of adverse events can be estimated, and other groups for whom the risk cannot be estimated.

To enable more evidence-informed decisions about whom to treat with TXA, we conducted a systematic review to delineate which patient groups are commonly excluded from clinical trials of perioperative TXA in cardiac surgery. This will help determine if there are patient populations in whom the risk of TXA therapy cannot be estimated. We hope the findings of this review will enable the development of evidence-informed exclusion criteria for TXA use in patients undergoing cardiac surgeries, and consequently minimize unnecessary withholding of TXA from patients who could safely benefit from the therapy. As a secondary objective, we evaluated the safety of systemic TXA in cardiac surgery.

\section{Methods}

This systematic review presents results of the cardiac surgery sub-study from a larger systematic review on exclusion criteria used in perioperative TXA trials in all surgical specialties. ${ }^{15}$ The protocol for the main systematic review can be found on PROSPERO (CRD42017060971). 
Eligibility criteria

The population of interest was patients undergoing any elective or emergent cardiac surgery. The intervention was systemic TXA (intravenous) administered at any point perioperatively, and at any dose, duration, and frequency. Eligible comparator groups were placebo, no intervention, or an active comparator. Our primary outcome of interest was the exclusion criteria of each study. As a secondary outcome, we evaluated the safety of TXA by collecting data on adverse events. To be eligible, studies had to report at least one of our outcomes of interest. We included only randomized-controlled trials (RCTs) that were full-text, peer-reviewed, and written in English or French.

We excluded duplicate publications, systematic reviews and meta-analyses, and non-randomized study designs. Studies without a comparator group were also excluded. RCTs administering TXA to non-surgical, or not fully surgical, patient population were not included. Additionally, studies including participants other than cardiac surgery patients were excluded. Finally, studies written in languages other than English or French were excluded.

\section{Search strategy}

A comprehensive search strategy with relevant keywords and $\mathrm{MeSH}$ terms was developed by an information specialist. The databases Medline (Ovid), EMBASE (Ovid), and the Cochrane Central Register of Controlled Trials were searched from inception until September 2017 without limits or restrictions. Additionally, grey literature was identified by searching clincialtrials.gov for completed RCTs.

\section{Article selection and data abstraction}

Four reviewers independently performed article selection and data abstraction. Citations retrieved from the database search were screened based on title and abstract, and relevant articles were read in full-text. Eligible studies were abstracted using a piloted, standardized form. Because of the large number of citations retrieved from the search, it was not practical to conduct article screening in duplicate. Nevertheless, all data abstraction was reviewed by a second reviewer to ensure accuracy.

Data analysis

A descriptive synthesis was performed to describe study characteristics and to identify the exclusion criteria of perioperative TXA RCTs in cardiac surgery. To evaluate the safety of TXA, meta-analysis of adverse events was performed using a Der Simonian and Laird random effects model. Meta-analysis was done separately for different comparator groups (e.g., placebo or no intervention, aminocaproic acid, aprotinin), given sufficient data (i.e., at least two studies). Meta-analysis was done overall for all adverse events, and specifically for thrombotic events (deep vein thrombosis, pulmonary embolism) and their sequelae (myocardial infarction, stroke), all of which are of concern in cardiac surgery. Meta-analysis was also performed specifically for seizures, given recent evidence suggesting that higher doses of TXA may be associated with this adverse event. ${ }^{1,14}$ Open Meta Analyst (http:// www.cebm.brown.edu/openmeta/) was used to generate forest plots, and results are shown as risk ratios (RRs) and 95\% confidence intervals (CIs). A correction factor of 0.5 was used for studies with zero total events. Funnel plots were generated using RevMan version 5 (Cochrane Collaboration, Oxford, UK).

Given that studies with short follow-up duration may not capture all adverse events related to TXA use, we performed a sensitivity analysis for the safety of TXA including only studies with a long duration of follow-up, which we defined as being one month or greater. Random effects meta-analysis was performed on these studies to determine the risk of adverse events.

\section{Post hoc analysis}

We performed a post hoc analysis guided by our findings from the exclusion criteria analysis to determine whether the most common reasons for excluding patients from cardiac surgery TXA trials were necessary for patient safety. We compared risks of adverse events in studies that had enforced a given exclusion criterion and studies that did not have the exclusion criterion. Random effects metaanalysis, as described above, was performed to calculate the relative risks. There were sufficient data to compare TXA with placebo and no intervention, but not with other comparator groups.

Risk of bias and overall quality of evidence assessment

Risk of bias was assessed for each study using the Cochrane risk of bias tool for RCTs. ${ }^{16}$ Publication bias was assessed with a funnel plot for our main meta-analysis (overall risk of adverse events). The overall quality of evidence generated by this systematic review was evaluated using GRADE methodology. ${ }^{17}$ 


\section{Results}

Database search results

Database and grey literature searching retrieved a total of 2,776 citations. After duplicate removal, 1,273 citations remained, which were screened based on title and abstract. Four hundred and eighty-six relevant studies were read in full-text, and 416 ineligible articles were excluded with reasons documented (Fig. 1). Seventy RCTs were eligible for inclusion in this systematic review (eAppendix A, available as Electronic Supplementary Material [ESM]). Of these, 55 trials reported adverse events and were eligible for meta-analysis.

\section{Summary of included studies}

A summary of the 70 included studies is presented in Table 1. Studies were published between 1990 and 2017, with the majority (70\%) published before 2010. A variety of cardiac surgeries were included, the most common one being coronary artery bypass graft surgery (47\%), followed by valve surgery $(7 \%)$, congenital heart surgery $(4 \%)$, and repeat cardiac surgery (4\%). Twenty-six studies (37\%) included patients undergoing multiple types of cardiac surgery. Patients were primarily adults (94\% of studies), with only four studies $(6 \%)$ investigating pediatric populations. Studies were variable with respect to the dose, timing, duration, and frequency of systemic TXA administration. Systemic TXA was compared with placebo ( $73 \%$ of studies), no intervention ( $7 \%$ of studies), aprotinin (34\% of studies), aminocaproic acid (9\% of studies), and topical TXA (1\% of studies). Some RCTs used more than one comparator group. The majority of studies were double blind $(76 \%$ ), while $2.9 \%$ were single blind and $10 \%$ were open-label. Blinding status of participants and study personnel was not specified in $11 \%$ of the trials.

\section{Exclusion criteria analysis}

A complete list of the exclusion criteria used in perioperative TXA cardiac surgery trials is shown in Table 2. The two most common reasons for excluding patients from these trials were major hepatic, renal, or cardiac comorbidities (76\% of studies), and use of medications affecting coagulation (56\% of studies). Other patient groups frequently excluded from these trials were those with coagulopathy ( $41 \%$ of studies), known allergy to TXA $(36 \%)$, an abnormal coagulation profile (33\% of studies), a previous history of arterial or venous thromboembolic (VTE) events (27\% of studies), and anemia (20\% of studies). Forty-nine percent of perioperative TXA RCTs in cardiac surgery also had exclusion criteria related to patient age (Table 2).

\section{Safety of TXA}

Meta-analysis of adverse events was performed to evaluate the safety of TXA (Table 3, Fig. 2). There were sufficient data to compare systemic TXA with placebo and no intervention, aprotinin, and aminocaproic acid, but not with topical TXA (Table 3). Overall, perioperative intravenous TXA did not increase the risk of adverse events compared with placebo or no intervention (RR, 0.97; 95\% CI, 0.88 to 1.07) (Fig. 2). Based on four RCTs, there was no significant difference in the risk of adverse events for patients receiving systemic TXA compared with aminocaproic acid (RR, 1.03; 95\% CI, 0.97 to 1.10). Compared with aprotinin, systemic TXA significantly decreased the risk of adverse events by $7 \%$ (RR, 0.93; $95 \%$ CI, 0.88 to 0.98 ).

Subgroup meta-analysis was done for thrombotic and seizure adverse events, as these are of particular concern with TXA use in cardiac surgery. We found that systemic TXA did not significantly increase the risk of VTE events, myocardial infarction, stroke, or seizure postoperatively compared with placebo, no intervention, aprotinin, and aminocaproic acid (Table 3).

\section{Sensitivity analysis (TXA safety)}

Given that duration of patient follow-up can affect the detection of adverse events in clinical trials, we performed a sensitivity analysis for the safety of TXA including only studies with a long follow-up period (one month or more). Nine studies (13\%) followed patients for one month or longer to monitor adverse events, and were included in this sensitivity analysis. Five studies compared perioperative systemic TXA to placebo, while four compared TXA to aprotinin. Meta-analysis showed that there was no significant difference in risk of adverse events between patients receiving systemic TXA and those administered a placebo (RR, 0.94; 95\% CI, 0.83 to 1.07). Compared with aprotinin, TXA was associated with a significant $10 \%$ decrease in the risk of adverse events (RR, 0.90; 95\% CI, 0.84 to 0.95$)$.

\section{Post hoc analysis}

The most frequent reason for excluding patients was the presence of major cardiac, renal, or hepatic comorbidities (76\% of studies). We compared the risks of adverse events in studies that excluded these patients $(n=53)$ with studies that included them ( $n=17$, of which 13 reported adverse events and were eligible for analysis). In studies that 

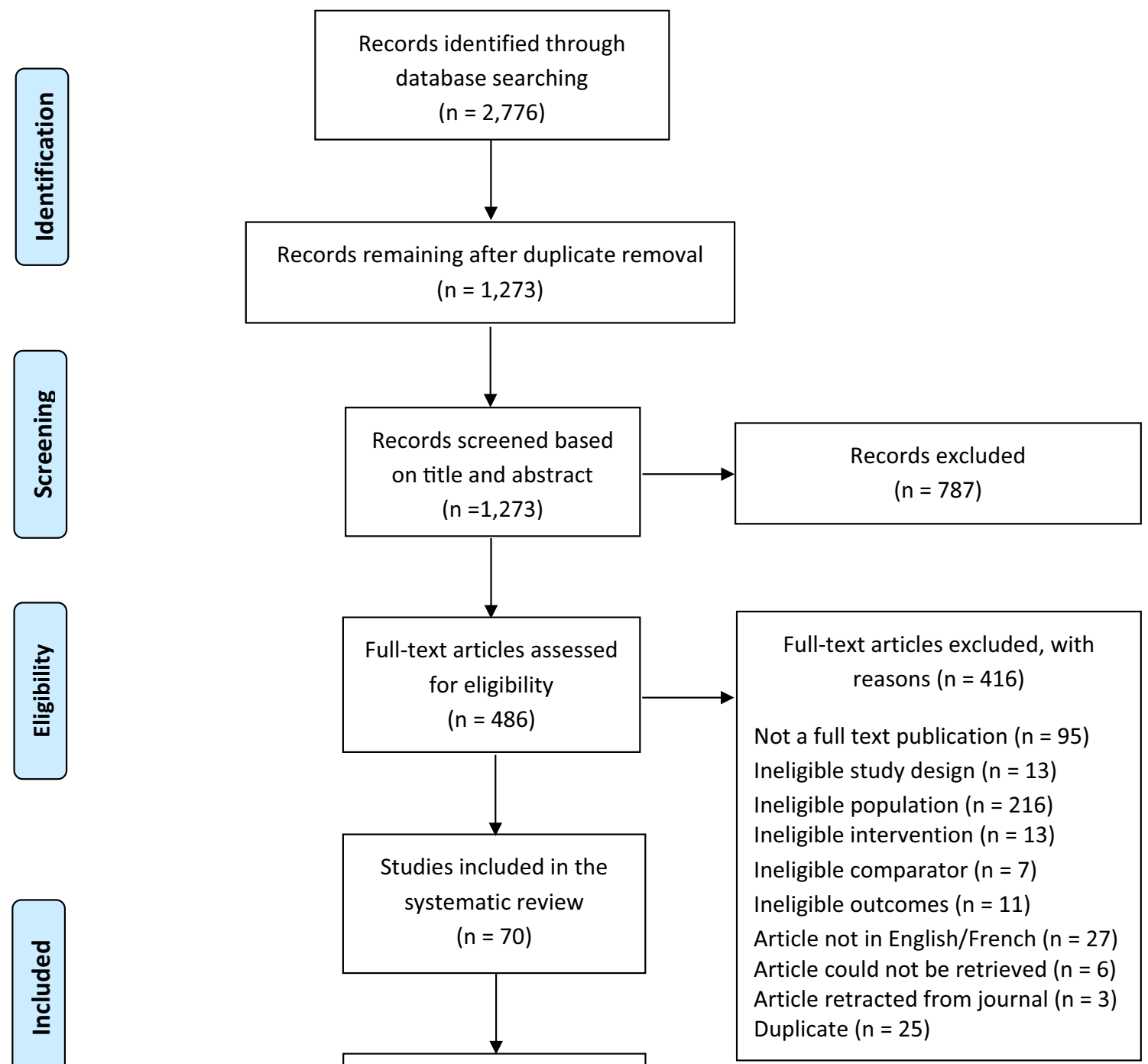

Studies included in the adverse events metaanalysis $(n=55)$

Fig. 1 PRISMA flowchart of the study selection process

excluded patients with major comorbidities, the overall risk of adverse events was 0.98 (95\% CI, 0.88 to 1.08) compared with control, whereas in studies that included these patients the risk was 0.75 (95\% CI, 0.40 to 1.43 ) compared with control. This suggests that risk of adverse events is not increased when patients with major renal, hepatic, and cardiac comorbidities are included in cardiac surgery TXA trials.

The second most common reason for excluding patients was use of medication affecting coagulation (56\% of studies). There were 39 studies that excluded these patients, of which 26 were eligible for meta-analysis, and 31 studies that included these patients, of which 20 could be used for meta-analysis. The overall risk of adverse events was 0.97 (95\% CI, 0.87 to 1.07) compared with control for studies that excluded patients on medication affecting coagulation, whereas the risk was 1.07 (95\% CI, 0.91 to 1.46 ) for studies that did not exclude this patient group. The similar and non-statistically significant risks of adverse events suggest that excluding patients taking medication affecting coagulation from TXA in cardiac surgery may not be necessary.

Another frequent reason for patient exclusion was coagulopathy (41\% of studies), with 29 studies excluding this patient group from cardiac surgery TXA trials, and 41 studies accepting such patients. Twenty-one and 19 studies, 
Table 1 Summary of characteristics of included studies $(n=70)$

\begin{tabular}{lc}
\hline Study characteristic & $n(\%)$ \\
\hline Cardiac surgery type & $33(47)$ \\
CABG & $5(7)$ \\
Valve & $3(4)$ \\
Congenital & $3(4)$ \\
Repeat cardiac surgery & $26(37)$ \\
Multiple types of cardiac surgery & \\
Patient age & $66(94)$ \\
Adult & $4(6)$ \\
Pediatric & \\
Comparator groups* & $51(73)$ \\
Placebo & $5(7)$ \\
No intervention & $24(34)$ \\
Aprotinin & $6(9)$ \\
ACA & $1(1)$ \\
Topical TXA & \\
Blinding & $53(76)$ \\
Double blind & $2(3)$ \\
Single blind & $7(10)$ \\
No blinding & $8(11)$ \\
Unclear & \\
\hline
\end{tabular}

*The sum of percentages will exceed $100 \%$, as some studies had more than one comparator group. $\mathrm{ACA}=$ aminocaproic acid; $\mathrm{CABG}=$ coronary artery bypass graft; TXA $=$ tranexamic acid

respectively, were eligible for meta-analysis. For studies excluding patients with coagulopathy, the overall risk of adverse events was 0.97 (95\% CI, 0.86 to 1.10) compared with controls, whereas in studies that accepted these patients the risk of adverse events was 1.02 (95\% CI, 0.73 to 1.44). This analysis suggests that excluding patients with coagulopathy from receiving TXA is not necessary in cardiac surgery.

Risk of bias and overall quality of evidence assessments

The overall risk of bias was low for the 70 perioperative cardiac surgery TXA trials. Nevertheless, there was an unclear risk of selective reporting bias, because the large majority of studies did not have a published protocol, meaning selective outcome reporting could not be assessed. Additionally, allocation concealment procedures were frequently not specified, leading to an unclear risk of selection bias.

Publication bias was assessed with a funnel plot (see eAppendix B, available as ESM). The funnel plot showed no obvious signs of asymmetry and publication bias.

The overall quality of evidence synthesized by this systematic review was rated as "moderate" based on the GRADE criteria. The full GRADE evidence profile can be found in eAppendix C (available as ESM). The body of evidence was downgraded from high quality to moderate quality because of imprecision in several of the metaanalyses (Table 3).

\section{Discussion}

Perioperative blood loss requiring transfusion is an important potential complication in cardiac surgery. ${ }^{8}$ Antifibrinolytic therapy with TXA is a common blood conservation strategy and multiple studies have shown it to be a safe and efficacious drug. . $^{3,8,18-21}$ Nevertheless, there remains a fear of using antifibrinolytics because of the potential for thrombotic events and seizures. In this systematic review, we examined 70 RCTs of systemic, intravenous TXA in cardiac surgeries to delineate which patient groups were commonly excluded from such trials and to evaluate the safety of TXA.

Evaluation of the exclusion criteria applied in cardiac surgery TXA RCTs showed that certain patient populations were frequently excluded from these trials. These were patients with major renal, hepatic, and cardiac comorbidities, patients using medications affecting coagulation, patients with known coagulopathy, patients with TXA allergy, patients with an abnormal coagulation profile, and patients with a history of thromboembolism. It is expected that patients with an allergy to TXA would be excluded from these trials, however, the reasons for the exclusion of the other patient groups are debatable.

There is abundant evidence for the safety of TXA in patients with cardiac disease, including two very large, high quality RCTs of patients undergoing cardiac surgery. ${ }^{1,18}$ Many of the patients in these trials also had renal impairment and did not suffer complications at rates higher than placebo-treated patients. ${ }^{1,18}$ This suggests that patients with renal and cardiac comorbidities should not be restricted from receiving TXA perioperatively during cardiac surgery. Additionally, we performed a post hoc analysis that compared risks of adverse events between studies that had included patients with major renal, cardiac and hepatic comorbidities, and studies that had excluded these patient groups. We found that the risk of adverse events was not increased when patients with major comorbidities were included in cardiac surgery TXA trials. It should be noted, however, that as TXA is eliminated by the kidneys, patients with renal impairment are likely to have prolonged elevated levels of TXA, and as such, may require alternate dosing regimens to avoid excessive TXA concentrations. ${ }^{22,23}$ Nevertheless, the significance of prolonged presence of TXA in plasma is unknown. The potential for increased rates of venous or arterial thromboembolism in these patients is likely little 
Table 2 Exclusion criteria of perioperative TXA trials in cardiac surgery $(n=70)$

\begin{tabular}{|c|c|}
\hline Exclusion criteria & $\begin{array}{l}\text { RCTs with exclusion } \\
\text { criteria } \\
n(\%)^{* \dagger}\end{array}$ \\
\hline Major comorbidities & $53(76)$ \\
\hline Renal dysfunction & $53(76)$ \\
\hline Hepatic dysfunction & $28(40)$ \\
\hline Cardiac dysfunction & $13(19)$ \\
\hline Heart failure & $5(7)$ \\
\hline Coronary artery disease & $2(3)$ \\
\hline Ischemic heart disease & $1(1)$ \\
\hline Medication affecting coagulation & $39(56)$ \\
\hline Anticoagulants & $24(34)$ \\
\hline NSAIDS & $16(23)$ \\
\hline Antiplatelets & $14(20)$ \\
\hline Hormones & $2(3)$ \\
\hline DVT prophylaxis & $1(1)$ \\
\hline Age & $34(49)$ \\
\hline \multicolumn{2}{|l|}{ Less than: } \\
\hline 8 months & $2(3)$ \\
\hline $18 \mathrm{yr}$ & $21(30)$ \\
\hline $40 \mathrm{yr}$ & $2(3)$ \\
\hline \multicolumn{2}{|l|}{ Greater than: } \\
\hline $65 \mathrm{yr}$ & $4(6)$ \\
\hline $80 \mathrm{yr}$ & $12(17)$ \\
\hline Coagulopathy & $29(41)$ \\
\hline Family history of coagulopathy & $1(1)$ \\
\hline Allergy to TXA & $25(36)$ \\
\hline Abnormal coagulation profile & $23(33)$ \\
\hline Low platelet count & $15(21)$ \\
\hline Elevated prothrombin time & $7(10)$ \\
\hline Elevated INR & $3(4)$ \\
\hline Elevated partial thromboplastin time & $3(4)$ \\
\hline $\begin{array}{l}\text { Previous history of thromboembolic } \\
\text { events }\end{array}$ & $19(27)$ \\
\hline Cerebrovascular accident & $7(10)$ \\
\hline Deep vein thrombosis & $6(9)$ \\
\hline Myocardial infarction & $4(6)$ \\
\hline Pulmonary embolism & $3(4)$ \\
\hline Any arterial thrombosis & $2(3)$ \\
\hline $\begin{array}{l}\text { Family history of thromboembolic } \\
\text { events }\end{array}$ & $2(3)$ \\
\hline Anemia & $14(20)$ \\
\hline Emergency surgery & $12(17)$ \\
\hline Hematologic disease & $12(17)$ \\
\hline Refusal of blood product transfusion & $8(11)$ \\
\hline Weight & $7(10)$ \\
\hline$<40 \mathrm{~kg}$ & $4(6)$ \\
\hline$>100 \mathrm{~kg}$ & $4(6)$ \\
\hline Hematuria & $6(9)$ \\
\hline Cerebrovascular disease & $4(6)$ \\
\hline
\end{tabular}

Table 2 continued

\begin{tabular}{ll}
\hline Exclusion criteria & $\begin{array}{l}\text { RCTs with exclusion } \\
\text { criteria } \\
n(\%)^{* \dagger}\end{array}$ \\
\hline Disseminated intravascular coagulation & $\mathbf{4}(\mathbf{6})$ \\
Ophthalmologic pathology & $\mathbf{4}(\mathbf{6})$ \\
Biliary pathology & $\mathbf{3}(\mathbf{4})$ \\
Peptic ulcer & $\mathbf{3}(\mathbf{4})$ \\
Subarachnoid hemorrhage & $\mathbf{3}(\mathbf{4})$ \\
BMI & $\mathbf{2}(\mathbf{3})$ \\
$<18$ & $2(3)$ \\
$>35$ & $1(1)$ \\
Leukemia & $\mathbf{2}(\mathbf{3})$ \\
Breastfeeding & $\mathbf{1}(\mathbf{1})$ \\
Epilepsy & $\mathbf{1}(\mathbf{1})$ \\
Low risk surgery & $\mathbf{1}(\mathbf{1})$ \\
Respiratory disease & $\mathbf{1}(\mathbf{1})$ \\
Use of antibiotics & $\mathbf{1}(\mathbf{1})$ \\
Vascular disease & $\mathbf{1}(\mathbf{1})$
\end{tabular}

Most frequent reasons for exclusions are given in bold

BMI = body mass index; DVT = deep vein thrombosis; INR = international normalized ratio; NSAIDS, non-steroidal antiinflammatory drugs; RCTs $=$ randomized-controlled trials

*Totals in bold are the number of studies having one or more exclusion criteria for a given exclusion criteria category. ${ }^{\dagger}$ Percentages are calculated using the 70 studies included in this systematic review as the denominator

cause for concern if patients are receiving standard postoperative anticoagulant and anti-platelet medications.

Our post hoc analysis found that excluding patients with coagulopathy or patients taking medications affecting coagulation from TXA therapy in cardiac surgery may not be necessary, as risks of adverse events were similar and not statistically significant in both studies that had accepted such patients and studies that had excluded these patient groups.

Regarding the exclusion of patients with a history of thromboembolic events, there are several lines of evidence to suggest that use of TXA is not precluded in these patients. Firstly, the elimination half-life of TXA is quite short, suggesting that its effect would not continue long into the postoperative period. ${ }^{24}$ Secondly, the use of postoperative VTE prophylaxis is recommended for many types of surgery and is of key importance in the prevention of VTE. ${ }^{25,26}$ Thirdly, there is substantial evidence from RCTs and systematic reviews, including the present study, showing that TXA does not increase the risk of VTE events. ${ }^{1,7,8,18}$ Furthermore, in a previous publication by our group that looked at exclusion criteria in TXA trials of various surgery types, we found no increased risk of VTE in studies that included patients with a history of thromboembolism compared with studies that excluded 
Table 3 Summary of meta-analysis results for the risk of adverse events in patients exposed to perioperative systemic TXA $v s$ a comparator in cardiac surgery trials. Meta-analysis was done for all adverse events overall, and for thrombotic and seizure events specifically

\begin{tabular}{|c|c|c|}
\hline Analysis & No. of studies & RR (95\% CIs) \\
\hline \multicolumn{3}{|l|}{ 1) Overall (all AEs) } \\
\hline Systemic TXA vs placebo/no intervention & 44 & 0.97 (0.88 to 1.07$)$ \\
\hline Systemic TXA vs ACA & 4 & $1.03(0.97$ to 1.10$)$ \\
\hline Systemic TXA vs aprotinin & 21 & $0.93(0.88 \text { to } 0.98)^{*}$ \\
\hline \multicolumn{3}{|l|}{ 2) Thrombosis AEs } \\
\hline \multicolumn{3}{|l|}{ Myocardial infarction } \\
\hline Systemic TXA vs placebo/no intervention & 24 & $0.91(0.79$ to 1.06$)$ \\
\hline Systemic TXA vs ACA & 3 & $1.38(0.83$ to 2.33$)$ \\
\hline Systemic TXA $v s$ aprotinin & 14 & $1.00(0.71$ to 1.40$)$ \\
\hline \multicolumn{3}{|l|}{ Stroke } \\
\hline Systemic TXA vs placebo/no intervention & 21 & $0.92(0.63$ to 1.34$)$ \\
\hline Systemic TXA vs ACA & 3 & $1.31(0.77$ to 2.24$)$ \\
\hline Systemic TXA $v s$ aprotinin & 9 & $1.12(0.70$ to 1.79$)$ \\
\hline \multicolumn{3}{|l|}{ VTE (DVT or PE) } \\
\hline Systemic TXA vs placebo/no intervention & 24 & $1.12(0.57$ to 2.18$)$ \\
\hline Systemic TXA vs ACA & 2 & $1.03(0.39$ to 2.70$)$ \\
\hline Systemic TXA $v s$ aprotinin & 10 & $0.97(0.46$ to 2.07$)$ \\
\hline \multicolumn{3}{|l|}{ 3) Seizure or convulsion } \\
\hline Systemic TXA vs placebo/no intervention & 9 & $1.85(0.84$ to 4.07$)$ \\
\hline
\end{tabular}

$\mathrm{ACA}=$ aminocaproic acid; $\mathrm{AE}=$ adverse event CIs = confidence intervals; $\mathrm{DVT}=$ deep vein thrombosis; $\mathrm{PE}=$ pulmonary embolism; $\mathrm{RR}=$ relative risk; TXA = tranexamic acid; VTE $=$ venous thromboembolic

*Denotes a statistically significant result $(P<0.05)$

these patients. ${ }^{15}$ Overall, there appears to be no reason to fear VTE events from TXA use even in patients with a previous history of thromboembolism, particularly when appropriate VTE prophylaxis is administered.

Based on moderate quality evidence, we found that perioperative systemic TXA use in cardiac surgeries did not increase the overall risk of adverse events compared with placebo, no intervention, or aminocaproic acid. Confidence intervals were narrow for these analyses, indicating a high degree of certainty and precision. Cmpared with aprotinin, systemic TXA was associated with a significant $7 \%$ decreased risk of adverse events. Our sensitivity analysis, which looked only at studies having a long period of follow-up to monitor adverse events, supported our findings on the safety of TXA in cardiac surgery. These findings are consistent with those of previous systematic reviews and RCTs analyzing the safety of systemic TXA. ${ }^{7,8,18-21}$

While concerns over seizure following TXA administration have been highlighted by previous studies, ${ }^{1,14}$ our meta-analysis found no significant increased risk of seizure in patients receiving TXA compared with patients on placebo or no intervention, although CIs were wide indicating some uncertainty. It should be noted that the concern about increased risk of seizure was following high doses of TXA, ${ }^{1,14}$ however, only three of our included studies that reported on seizures administered TXA at a high dose, ${ }^{1,27,28}$ while the rest administered low or moderate doses.

Regarding concerns of thrombosis from TXA use, we found no increased risk of thrombotic events following TXA use, compared with placebo, no intervention, aminocaproic acid, and aprotinin. Coronary thrombosis may be of particular concern in patients with a recent coronary stent. ${ }^{29}$ While we did not specifically evaluate patients with previous stents, we found no increased risk of arterial thrombosis associated with TXA use. Additionally, the recent ATACAS trial of TXA in cardiac surgery included similar numbers of patients with previous stents in both study arms (TXA versus placebo), and reported no increased risk of thrombosis from TXA. ${ }^{30}$ Ensuring that recently stented patients are either not taken off antiplatelet medications or that these drugs are promptly resumed after surgery is likely of greater importance than the potential effect perioperative TXA may have on thrombosis.

While this review found TXA to be safe in cardiac surgery trials, the patient groups that were commonly excluded from these trials do have somewhat less data on the efficacy and safety of TXA because of their frequent 


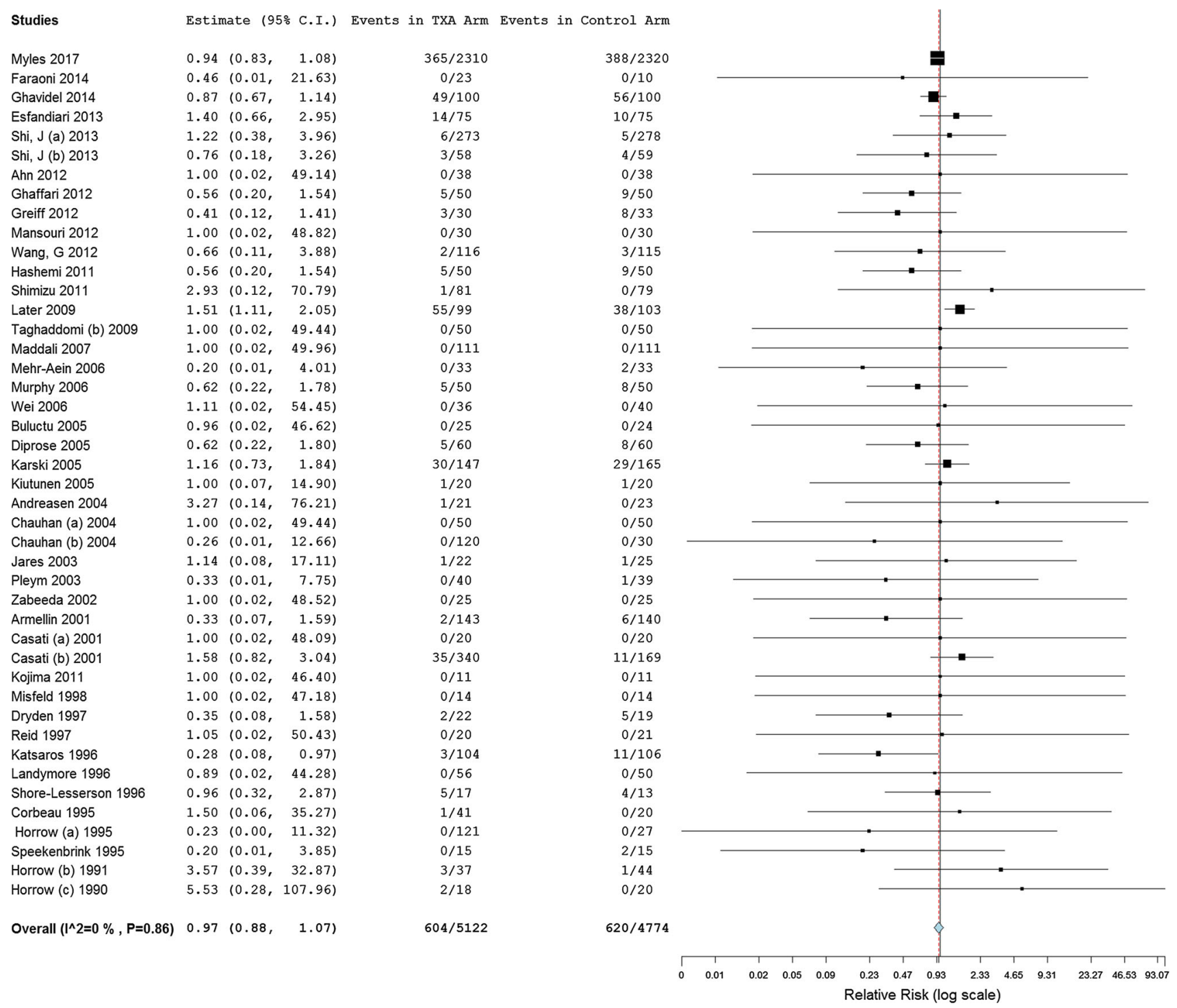

Fig. 2 Meta-analysis for the risk of adverse events in patients exposed to TXA compared with placebo or no intervention in cardiac surgery trials $(n=44)$. TXA $=$ tranexamic acid

exclusion from RCTs. As such, future studies examining the effectiveness and safety of TXA in these patient groups may be warranted.

Several limitations to our systematic review should be recognized. There was an unclear risk of selective outcome reporting due to RCTs frequently not publishing their protocols, as well as an unclear risk of selection bias as allocation concealment methods were often not disclosed. There is also the potential for language bias as we only included articles that were in English or French. Nevertheless, the number of articles excluded due to language restrictions was small, thus limiting the effect of language bias. Finally, a limitation of our post hoc metaanalyses that separated studies by exclusion criteria is that while some studies may not have implemented a given exclusion criterion, it is unknown how many patients with the criterion were actually enrolled in the study.

Despite these limitations, this systematic review is the first to analyze the exclusion criteria of RCTs involving TXA use in cardiac surgeries. From our findings, it may be possible to generate evidence-based guidelines to direct the safe utilization of TXA in cardiac surgery patients.

In conclusion, our systematic review showed that perioperative systemic TXA is a safe blood conservation technique in cardiac surgery. TXA did not increase the risk of adverse events, including seizures and thrombotic complications, compared with placebo, no intervention, and aminocaproic acid. Despite this, certain patient groups were commonly excluded from TXA trials in cardiac surgery, including those with major renal, hepatic, and 
cardiac comorbidities, those using medications affecting hemostasis, those with known coagulopathy, those with an abnormal coagulation profile, and those with a history of thromboembolism. Further evaluation of TXA use in these patient groups may be warranted, but sufficient information exists to direct evidence-guided recommendations regarding the use of TXA in cardiac surgery.

Acknowledgements We thank Dr. Benjamin Sohmer and Dr. Sean Dickie for their advice and expertise in the field of cardiac surgical anesthesia.

Conflicts of interest Dr. Tinmouth is a consultant for Canadian Blood Services. The remaining authors have no conflicts of interest to disclose.

Editorial responsibility This submission was handled by Dr. Philip M. Jones, Associate Editor, Canadian Journal of Anesthesia.

Author contributions Elianna Saidenberg, Alan Tinmouth, Jacinthe Lampron, and Jeffrey Yates conceived the idea and design for this systematic review and meta-analysis. Jeffrey Yates, Iris Perelman, Simonne Khair, and Joshua Taylor performed all aspects of article selection and data abstraction. Jeffrey Yates and Iris Perelman conducted data analysis. Simonne Khair and Iris Perelman drafted the manuscript, with contributions and critical review from all other authors.

Funding This work did not receive any funding.

\section{References}

1. Myles PS, Smith JA, Forbes A, et al. Tranexamic acid in patients undergoing coronary-artery surgery. N Engl J Med 2017; 376: 136-48.

2. Vivacqua A, Koch CG, Yousuf AM, et al. Morbidity of bleeding after cardiac surgery: is it blood transfusion, reoperation for bleeding, or both? Ann Thorac Surg 2011; 91: 1780-90.

3. Henry DA, Carless PA, Moxey AJ, et al. Anti-fibrinolytic use for minimising perioperative allogeneic blood transfusion. Cochrane Database Syst Rev 2011; 3: CD001886.

4. Greiff $G$, Stenseth $R$, Wahba A, et al. Tranexamic acid reduces blood transfusions in elderly patients undergoing combined aortic valve and coronary artery bypass graft surgery: a randomized controlled trial. J Cardiothorac Vasc Anesth 2012; 26: 232-8.

5. Madershahian N, Scherner $M$, Pfister $R$, et al. Prophylactic intraoperative tranexamic acid administration and postoperative blood loss after transapical aortic valve implantation. J Cardiothorac Surg 2015; 10: 45.

6. Wang $G$, Xie $G$, Jiang $T$, et al. Tranexamic acid reduces blood loss after off-pump coronary surgery: a prospective, randomized, double-blind, placebo-controlled study. Anesth Analg 2012; 115: 239-43.

7. Ker K, Edwards P, Perel P, Shakur H, Roberts I. Effect of tranexamic acid on surgical bleeding: systematic review and cumulative meta-analysis. BMJ 2012; 344: e3054.

8. Adler Ma SC, Brindle W, Burton $G$, et al. Tranexamic acid is associated with less blood transfusion in off-pump coronary artery bypass graft surgery: a systematic review and metaanalysis. J Cardiothorac Vasc Anesth 2011; 25: 26-35.

9. Guerriero C, Cairns J, Perel P, Shakur H, Roberts I; CRASH 2 Trial Collaborators. Cost-effectiveness analysis of administering tranexamic acid to bleeding trauma patients using evidence from the CRASH-2 trial. PLoS One 2011; 6: e18987.

10. Ho KM, Bham E, Pavey $W$. Incidence of venous thromboembolism and benefits and risks of thromboprophylaxis after cardiac surgery: a systematic review and meta-analysis. J Am Heart Assoc 2015; 4: e002652.

11. Schwann TA, Kistler L, Engoren MC, Habib RH. Incidence and predictors of postoperative deep vein thrombosis in cardiac surgery in the era of aggressive thromboprophylaxis. Ann Thorac Surg 2010; 90: 760-6.

12. Society of Thoracic Surgeons Blood Conservation Guideline Task Force; Ferraris VA, Brown JR, Despotis GJ, et al. 2011 Update to the Society of Thoracic Surgeons and the Society of Cardiovascular Anesthesiologists Blood Conservation Clinical Practice Guidelines. Ann Thorac Surg 2011; 91: 944-82.

13. Pagano D, Milojevic M, Meesters MI, et al. 2017 EACTS/ EACTA Guidelines on patient blood management for adult cardiac surgery. Eur J Cardiothorac Surg 2018; 53: 79-111.

14. Murkin JM, Falter F, Granton J, Young B, Burt C, Chu M. Highdose tranexamic acid is associated with nonischemic clinical seizures in cardiac surgical patients. Anesth Analg 2010; 110: 350-3.

15. Yates J, Perelman I, Khair $S$, et al. Exclusion criteria and adverse events in peri-operative trials of tranexamic acid: a systematic review and meta-analysis. Transfusion 2019; 59: 806-24.

16. Higgins JP, Altman DG, Gotzsche PC, et al. The Cochrane Collaboration's tool for assessing risk of bias in randomised trials. BMJ 2011; 343: d5928.

17. Balshem $H$, Helfand $M$, Schunemann HJ, et al. GRADE guidelines: 3 . Rating the quality of evidence. J Clin Epidemiol 2011; 64: 401-6.

18. Fergusson DA, Hébert PC, Mazer CD, et al. A comparison of aprotinin and lysine analogues in high-risk cardiac surgery. $\mathrm{N}$ Engl J Med 2008; 358: 2319-31.

19. Takagi H, Manabe H, Kawai N, Goto SN, Umemoto T. Aprotinin increases mortality as compared with tranexamic acid in cardiac surgery: a meta-analysis of randomized head-to-head trials. Interact Cardiovasc Thorac Surg 2009; 9: 98-101.

20. Schouten ES, van de Pol AC, Schouten AN, Turner NM, Jansen $N J$, Bollen $C W$. The effect of aprotinin, tranexamic acid, and aminocaproic acid on blood loss and use of blood products in major pediatric surgery: a meta-analysis. Pediatr Crit Care Med 2009; 10: 182-90.

21. Brown JR, Birkmeyer NJ, O'Connor GT. Meta-analysis comparing the effectiveness and adverse outcomes of antifibrinolytic agents in cardiac surgery. Circulation 2007; 115: 2801-13.

22. Jerath A, Yang QJ, Pang KS, et al. Tranexamic acid dosing for cardiac surgical patients with chronic renal dysfunction: a new dosing regimen. Anesth Analg 2018; 127: 1323-32.

23. Wasowicz $M$, Yang JQ, Bojko B, et al. Pharmacokinetics of tranexamic acid in cardiac surgical patients suffering from kidney dysfunction. Crit Care Med 2016; 44(Suppl. 1): 108 (abstract).

24. Pilbrant A, Schannong M, Vessman J. Pharmacokinetics and bioavailability of tranexamic acid. Eur J Clin Pharmacol 1981; 20: 65-72.

25. Falck-Ytter Y, Francis CW, Johanson NA, et al. Prevention of VTE in orthopedic surgery patients: Antithrombotic Therapy and Prevention of Thrombosis, 9th ed: American College of Chest Physicians Evidence-Based Clinical Practice Guidelines. Chest 2012; 141: e278S-325S 
26. Kearon C, Akl EA, Ornealas $J$, et al. Antithrombotic therapy for VTE disease: CHEST guideline and expert panel report. Chest 2016; 149: 315-52.

27. Sigaut $S$, Tremey B, Ouattara A, et al. Comparison of two doses of tranexamic acid in adults undergoing cardiac surgery with cardiopulmonary bypass. Anesthesiology 2014; 120: 590-600.

28. Bokesch PM, Szabo G, Wojdyga R, et al. A phase 2 prospective, randomized, double-blind trial comparing the effects of tranexamic acid with ecallantide on blood loss from high-risk cardiac surgery with cardiopulmonary bypass (CONSERV-2 Trial). J Thorac Cardiovasc Surg 2012; 143: 1022-9.
29. Bridges $\mathrm{KH}$, Wilson SH. Acute coronary artery thrombus after tranexamic acid during total shoulder arthroplasty in a patient with coronary stents: a case report. A A Pract 2018; 10: 212-4.

30. Myles PS, Smith JA, Kasza J, et al. Tranexamic acid in coronary artery surgery: one-year results of the Aspirin and Tranexamic Acid for Coronary Artery Surgery (ATACAS) trial. J Thorac Cardiovasc Surg 2019; 157(644-52): e9.

Publisher's Note Springer Nature remains neutral with regard to jurisdictional claims in published maps and institutional affiliations. 